Research Article

\title{
Caesarean Section: A Necessary Evil?
}

\author{
Abhishek Malakar', Shiv Shankar Singh ${ }^{2}$, Shreya Barik ${ }^{3}$, Dhanisha S Awaradi ${ }^{4}$ \\ ${ }^{1}$ Assistant Professor, ${ }^{3}$ Senior Resident, ${ }^{4}$ Internee, Department of Obstetrics and Gynaecology, ANIIMS, Port Blair, India. \\ ${ }^{2}$ Associate Professor, Department of General Medicine, ANIIMS, Port Blair, India.
}

DOI: https://doi.org/10.24321/2454.8642.201915

\section{I $\quad \mathbf{N} \quad \mathbf{F} \quad \mathbf{O}$}

\section{Corresponding Author:}

Shiv Shankar Singh, Department of Obstetrics and Gynaecology, ANIIMS, Port Blair, India.

E-mail Id:

diraniims@gmail.com

Orcid Id:

https://orcid.org/0000-0001-8544-6260

How to cite this article:

Malakar A, Singh SS, Barik S et al. Caesarean Section: A Necessary Evil? Rec Adv Path Lab Med 2019; 5(3): 8-13.

Date of Submission: 2019-07-25

Date of Acceptance: 2019-09-18

\section{$\begin{array}{llllllll}\mathbf{A} & \mathbf{B} & \mathbf{S} & \mathbf{T} & \mathbf{R} & \mathbf{A} & \mathbf{C} & \mathbf{T}\end{array}$}

Background: Caesarean Section (CS) has become more prevalent over the years due to various factors and is exceeding the specified limit laid down by the WHO. Caesarean section is associated with various maternal and neonatal morbidities. With the alarming rise in Caesarean Section rate, these complications invariably increase. We conducted this study to assess the maternal and neonatal morbidities associated with CS in a tertiary care hospital in Andaman and Nicobar Islands, India.

Methods: This was a prospective observational study done over a period of one year from January 2018 to December 2018. Data was collected for all CS performed in this time period and was statistically analysed by MS Excel, frequency distribution tables and SPSS Software.

Result: Over the study period of one year, there were total 2646 deliveries with caesarean rate of $38.51 \%$ and more than $75 \%$ of these were primary caesarean section. Almost three fourth (73.61\%) were emergency CS. Intraoperative adhesions and extension of uterine incision were common intraoperative complications whereas PPH was the most common post-operative morbidity. Intra operative complications were more in cases of emergency CS.

Conclusion: We found a high CS rate with a high percentage of primary caesarean section along with various complications. With advancement in better maternal and foetal monitoring in labour in a tertiary care centre, it is desirable to be able to provide a safer vaginal delivery to patients that promises a better obstetric future. The decision to perform a Caesarean delivery must be chosen carefully, balancing risks and benefits, and not liberally. This is only possible if standard guidelines and protocols of management are in place at national and institutional levels. Only then the overall primary CS rate and its complications can best be avoided.

Keywords: Andaman and Nicobar, CS Rate, Intra-Operative Complications, Indications of CS, Post-Operative Complications

\section{Introduction}

Caesarean section, which was mainly evolved as a lifesaving procedure for mother and foetus during difficult delivery, is one of the most widely performed surgical procedures in present day obstetrics. The use of CS as a mode of delivery has continued its worrying rise worldwide, in spite of the statement regarding ideal CS rate of $10-15 \%$ by WHO. ${ }^{1}$ 
In developed countries like US and UK, the rate of CS is approximately $24-40 \%$, whereas in India, rate of CS varies from $12-40 \%$ (NFHS IV). ${ }^{2-4}$

Childbirth, by its very nature, carries potential risks to mother and the baby. For some high-risk situations, caesarean delivery may be the safest mode of delivery, whereas for most low risk cases, caesarean delivery appears to pose a greater risk of maternal morbidity and mortality than vaginal delivery. There are concerns regarding both short term risks like excessive haemorrhage, anaesthetic complications, venous thromboembolism, infections as well as long term risks associated with subsequent pregnancies like scar rupture, placenta previa and morbidly adherent placenta. ${ }^{5}$ According to RCOG, all emergency CS itself or all elective CS in presence of other risk factor are considered as intermediate risk population for venous thromboembolism (VTE). ${ }^{6}$ New-borns too may face problems like neonatal respiratory distress including transient tachypnoea and persistent pulmonary hypertension. ${ }^{7}$

We conducted this study in Andaman and Nicobar Islands Institute of Medical Sciences (ANIIMS), which is the only tertiary care hospital of Andaman and Nicobar Islands. Our aim was to analyse various intra operative and postoperative maternal complications and neonatal morbidities associated with CS.

\section{Materials and Methods}

This was a prospective observational study conducted in Andaman and Nicobar Islands Institute of Medical Sciences, a tertiary care hospital in Andaman and Nicobar Islands. We collected data of all the caesarean sections done over one year, from January 2018 to December 2018. The age, parity of the patients and obstetrical parameters like gestational age at time of CS, type of CS, its indications, intra operative and post-operative complications and neonatal morbidities were noted. All patients whose data were collected were informed of the study prior to discharge from hospital and consent was obtained to use their information. Anonymity was maintained and all the cases in the study provided their consent. The total number of deliveries over the study period of one year was collected and caesarean section rate was determined by total number of caesarean deliveries out of total deliveries. We presented the data in table formats and analysed it using SPSS software. We calculated the association between types of CS with intra operative complications using Chi-square test. The study was approved by the institutional ethical committee.

\section{Result}

There were total 2646 deliveries over one year of study period, out of which 1019 were caesarean delivery, which makes the rate of caesarean section as $38.51 \%$. Age wise, majority (645 out of 1019 women) were in the age group of reproductive age group (21-30 years) with approximately one out of twenty women being elderly ( $\geq 35$ years). Only $15.01 \%$ women underwent CS before 37 completed weeks mostly due to maternal indications like severe preeclampsia or antepartum haemorrhage. Approximately three fourth of the total cases (73.6\%) were emergency CS whereas more than $75 \%$ were primary CS (Figure 1 and 2).

Figure 3 shows the different indications of caesarean section. Post Caesarean section pregnancy was the commonest indication (24.73\%) followed by foetal distress (15.11\%). Malpresentation, non-progress of labour, severe preeclampsia and failure of induction were the next common indications.

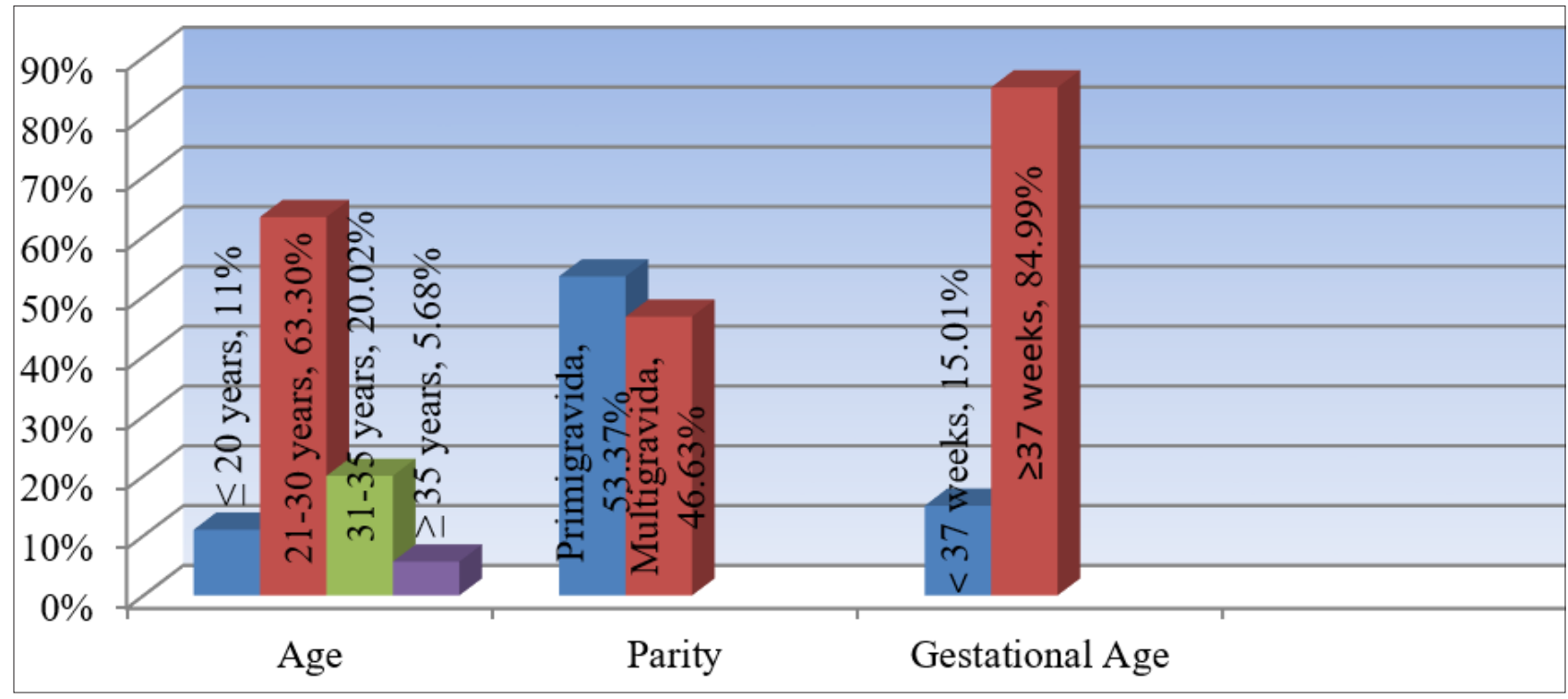

Figure I.Demographic parameters 


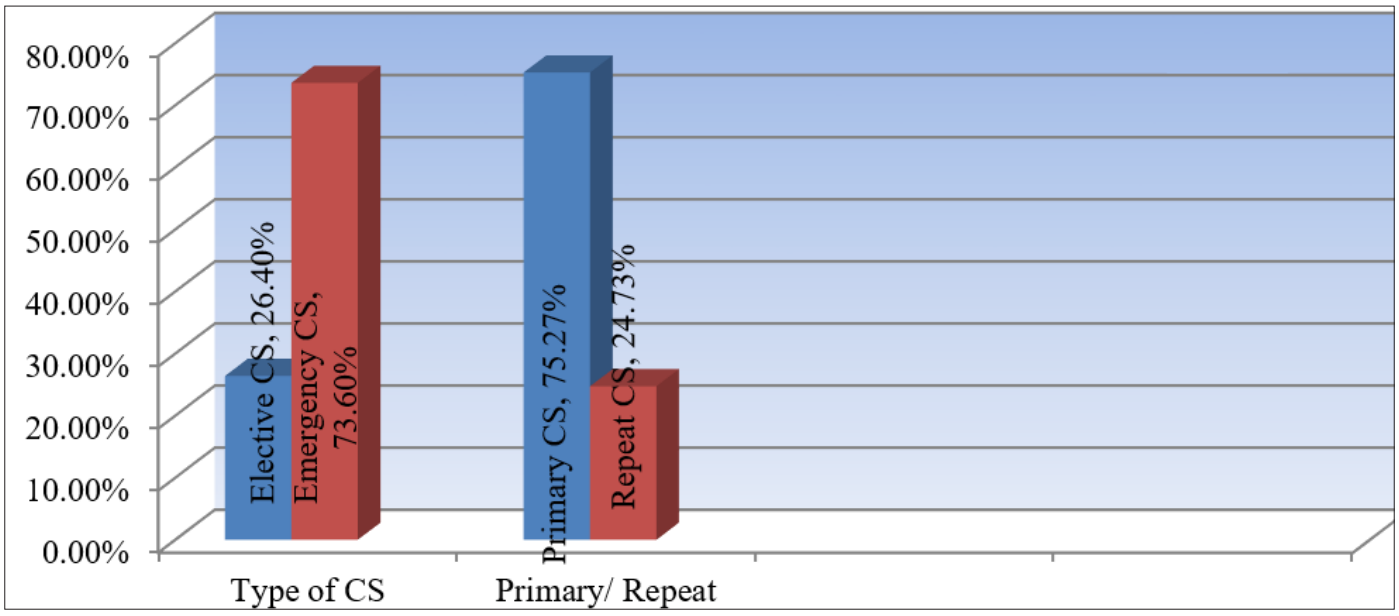

Figure 2.Types of CS

Table I.Distribution of cases according to intra-operative complications $(n=180$ out of 1019$)$

\begin{tabular}{|c|c|c|}
\hline Complications & No. of cases & Percentage (\%) \\
\hline Post-operative gross adhesions & 70 & $6.87 \%$ \\
\hline Extension of uterine incision & 50 & $4.91 \%$ \\
\hline Scar dehiscence & 32 & $3.14 \%$ \\
\hline Difficult delivery & 21 & $2.06 \%$ \\
\hline Intra operative atonic post-partum haemorrhage & 15 & $1.47 \%$ \\
\hline Placenta previa & 03 & $0.3 \%$ \\
\hline Bladder injury & 02 & $0.2 \%$ \\
\hline
\end{tabular}

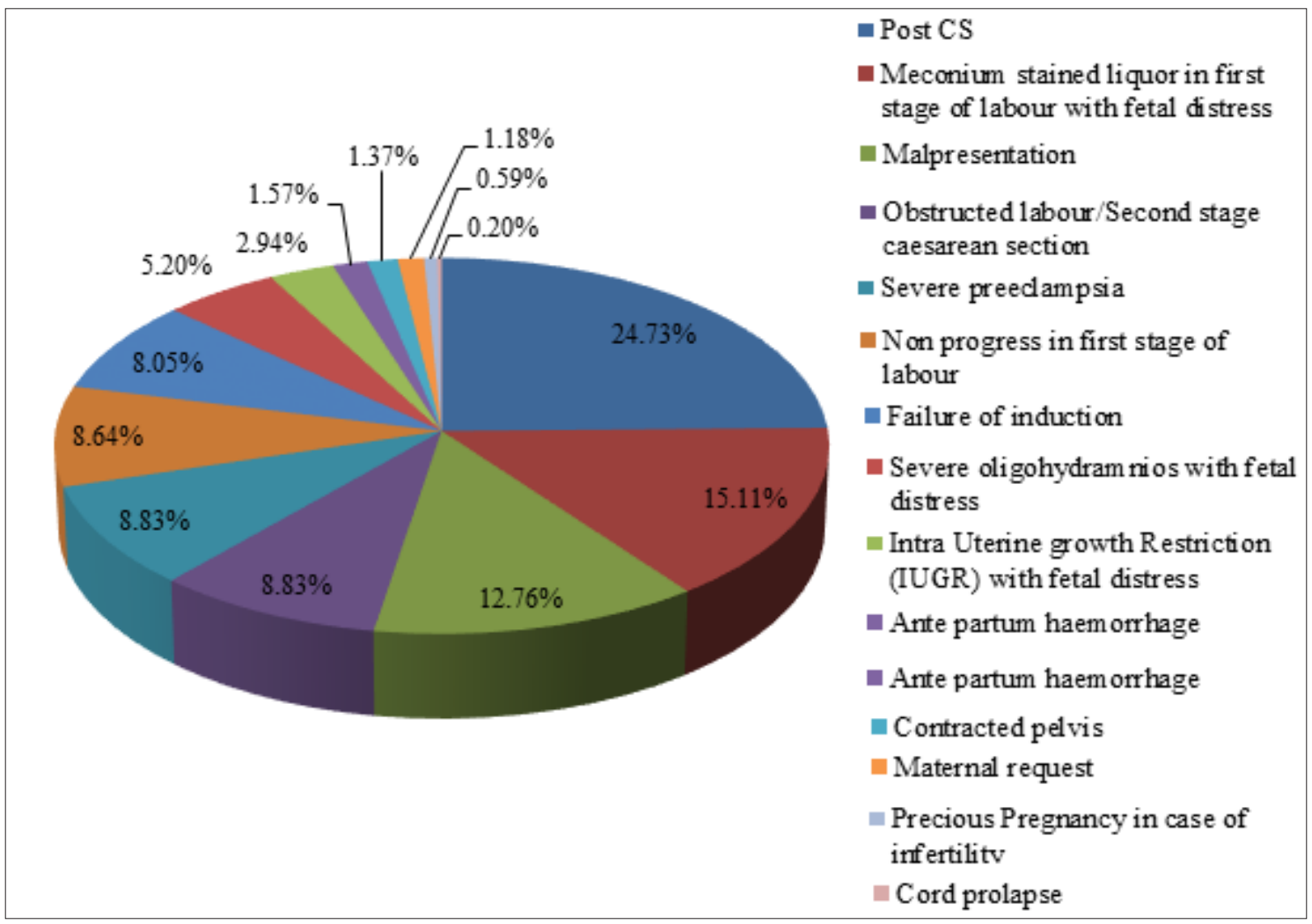

Figure 3.Various indications for caesarean section 
We studied the different intra operative complications and found post-operative gross adhesions (in post caesarean cases) and extension of uterine incision were the two most common complications experienced during the operations. 32 out of 252 post caesarean section women had scar dehiscence when they were taken for emergency CS. In 21 cases, baby delivery was difficult, most of which were cases of obstructed labour and transverse lie, some cases of the latter requiring extension of uterine incision. There were only two cases of bladder injuries, both were post CS cases with gross adhesions distorting normal anatomy. Injuries were diagnosed intraoperatively and managed with prompt repair with prolonged catheterisation (Table 1).

All the cases were properly monitored and post-operative complications were duly noted. PPH and paralytic ileus were the most common post-operative complications. Incidence of PPH among all CS was 5.88\% (60 out of 1019 women) and this population included those having intra operative PPH. All the cases were atonic PPH managed by uterotonics. There were two cases of DVT with incidence rate calculated as $0.2 \%$ (approximately) (Table 2 ).

Table 2.Distribution of cases according to postoperative complications $(n=\mid 62$ out of 1019$)$

\begin{tabular}{|c|c|c|}
\hline Complications & No. of cases & Percentage (\%) \\
\hline PPH & 60 & $5.89 \%$ \\
\hline Paralytic ileus & 40 & $3.93 \%$ \\
\hline Fever & 28 & $2.75 \%$ \\
\hline $\begin{array}{c}\text { Blood transfusion } \\
\text { infection }\end{array}$ & 25 & $2.45 \%$ \\
\hline $\begin{array}{c}\text { Urinary tract } \\
\text { infection }\end{array}$ & 09 & $1.47 \%$ \\
\hline $\begin{array}{c}\text { Respiratory tract } \\
\text { infection }\end{array}$ & 08 & $0.88 \%$ \\
\hline DVT & 02 & $0.2 \%$ \\
\hline
\end{tabular}

Table 3.Distribution of cases according to neonatal morbidity

\begin{tabular}{|c|c|c|}
\hline Neonatal morbidity & $\begin{array}{c}\text { No. of } \\
\text { cases }\end{array}$ & $\begin{array}{c}\text { Percentage } \\
\text { (\%) }\end{array}$ \\
\hline Birth asphyxia (Poor APGAR) & 116 & $11.38 \%$ \\
\hline $\begin{array}{c}\text { Meconium aspiration } \\
\text { syndrome }\end{array}$ & 56 & $5.5 \%$ \\
\hline $\begin{array}{c}\text { Transient tachypnoea of } \\
\text { Newborn (TTN) }\end{array}$ & 30 & $2.94 \%$ \\
\hline Sepsis & 30 & $2.94 \%$ \\
\hline Convulsions & 7 & $0.69 \%$ \\
\hline Stillborn & 2 & $0.2 \%$ \\
\hline
\end{tabular}

Table 3, revealed birth asphyxia was the commonest cause of neonatal morbidity and NICU admission. These were mostly the cases of foetal distress, obstructed labour and severe IUGR. There were two cases of stillbirth, one being a case of cord prolapse and the other was a case of severe abruptio placentae.

Table 4.Correlation between type of CS and intra operative complications

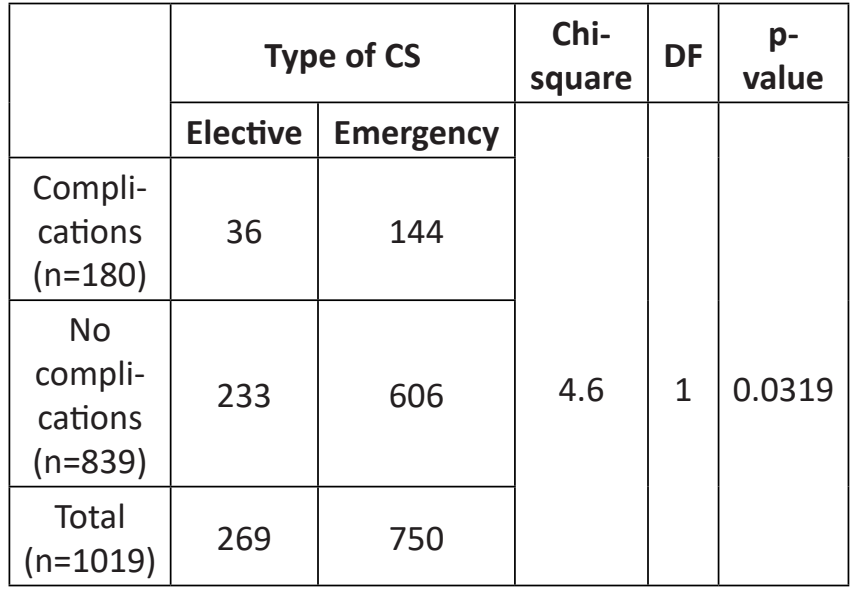

We determined the correlation between intra operative complications and types of CS, which showed intra operative complications were significantly more with emergency CS compared to elective CS. ( $p=0.0319)$ (Table 4).

\section{Discussion}

The rapid increase in caesarean birth rates over the past few years all over the world without clear evidence of concomitant decreases in maternal or neonatal morbidity or mortality raises significant concern that caesarean delivery is overused. ${ }^{8}$ The rate of caesarean section rates all over India varies widely from $25-50 \%$ as seen from various studies. ${ }^{9-13}$ The reason behind this wide variation is that there is no standard classification system and the definitions are also not standardized. ${ }^{14,15}$

We found the rate of CS as 38.51\% which was on the higher side due to our institute being the only referral centre of the whole Andaman and Nicobar Islands, leading to many high-risk cases and also cases in late stages of labour being referred here. Vaginal birth after caesarean was not widely practised in our institute. Other than total CS rate, another trend of CS is the rise in the rate of primary caesarean section. In our study, 767 out of 1019 (75.27\%) women underwent primary caesarean section. This rate was similar to a study on primary caesarean section rates by Desai $E$ et al (74.66\%) but more than the result by Jain $\mathrm{M}$ et al. (55.8\%) and Das RK et al. (63.41\%)..$^{12,16,17}$ Primary CS is obstetrically more important as it paves way for more repeat caesarean deliveries in future.

In different previous studies, post CS pregnancies constituted 
about $23-42 \%$ of all the CS done. ${ }^{12,18-20}$ In our study too, post caesarean pregnancy was the most common indication, followed by foetal distress (15.11\%). Three fourth of all the sections were emergency CS. A total of $17.47 \%$ of cases were taken for CS for arrest of labour, which was exactly similar to the finding of a study from western India (17.6\%). ${ }^{21}$ There are difficulties in transportation from distant islands and this results in a lot of referral of obstructed labour cases. Hence a significant proportion (8.83\%) of total CS was done in view of obstructed labour or second stage caesarean section.

For most low risk pregnancies, compared to vaginal delivery, caesarean delivery appears to pose greater risk of maternal mortality and morbidity. In our study, post-operative gross adhesions were the most common complication faced by obstetricians and due to high number of second stage $\mathrm{CS}$, extension of the uterine incision was common. We found that as all post CS women with scar tenderness and women with obstructed labour were taken as emergency cases, intra operative complications were significantly more in emergency CS, which is similar to the findings by Jain $\mathrm{M}$ et al. ${ }^{17}$ Chavda $\mathrm{D}$ et al. also showed in their study that complications like $\mathrm{PPH}$, intestinal injury, paralytic ileus and surgical site infection were more common in emergency $\mathrm{CS}^{19}$

Regarding post-operative complications, Megann EF et al. and Kumar $\mathrm{N}$ showed the incidence of $\mathrm{PPH}$ following CS being $4.84 \%-6.75 \%$ in their studies. ${ }^{22,23}$ We found $\mathrm{PPH}$ in $5.89 \%$ of all CS cases, which was similar to the findings by Desai E et al. (5.81\%) and Jain M et al. (5.7\%). ${ }^{16,17}$ There were forty cases of abdominal distension after CS, mostly done in cases of obstructed labour or second stage caesarean sections. We found two cases of DVT, who presented with unilateral leg pain and swelling, which were diagnosed by Doppler ultrasound and managed conservatively and there was no pulmonary embolism or mortality. Both the cases of DVT followed emergency CS, which is an intermediate risk factor for venous thromboembolism. ${ }^{6}$ Surgical site infection complicated only $1.47 \%$ of all CS contrary to the findings by Das RK et al. and Santhanalakshmi C et al., where it was the commonest complication. ${ }^{12,24}$

Caesarean section, especially elective CS and preterm CS increases respiratory morbidities of newborn. In one review of studies, the incidences of TTN varied from 0.3 to $3 \%$ for infants delivered vaginally, and from 0.9 to $12 \%$ for infants delivered by elective $\mathrm{CS} .{ }^{25}$ In our study, $2.94 \%$ of all infants delivered by CS suffered from TTN and 23 out of these 30 cases were elective CS. Meconium aspiration syndrome and birth asphyxia were common in sections done in view of foetal distress.

Limitations of this study were that we had not assessed long term complications of CS and we had not compared the maternal and neonatal complications of caesarean section with those of vaginal delivery.

\section{Conclusion}

Obstetric practice should be evidence based and aiming for a better maternal and neonatal outcome. Although in some high risk cases, caesarean section is definitely better than vaginal delivery, the injudicious practice of CS leading to a constant rising trend globally gives rise to various complications, thus compromising the overall possible benefits of CS. Keeping the complications associated with CS in mind, it is high time for the formulation of standard national guidelines for a country like India which can decrease the escalating CS rate and curb its associated maternal and neonatal morbidities.

\section{References}

1. WHO Statement on caesarean section rates. 2015. WHO reference number: WHO/RHR/15.02. Available from: http://www.who.int/reproductivehealth/publications/ maternal perinatal health/cs-statement/en.

2. National vital statistics report. 2012; 62(9). Available from: https://www.cdc.gov/nchs/products/nvsr.htm.

3. WHO Euro Health for all database, 2014. Available from: http://data.euro.who.int/hfadb/(53).

4. International Institute for Population Sciences (IIPS) and ICF. 2017. National Family Health Survey (NFHS-4), 2015-16: India. IIPS, Mumbai. Available from: http:// rchiips.org/NFHS/NFHS4Reports/India.pdf.

5. American College of Obstetricians and Gynaecologists. Safe prevention of the primary cesarean delivery. Obstetric Care Consensus No. 1. Obstet Gynaecol 2014; 123: 693-711.

6. Royal College of Obstetricians and Gynaecologists. Reducing the risk of venous thromboembolism during pregnancy and the puerperium. Green-top Guideline 37a. 2015.

7. Levine EM, Ghai V, Barton JJ et al. Mode of delivery and the risk for respiratory diseases in new-borns. Obstet Gynecol 2001; 97(3): 439-442.

8. Gregory KD, Jackson $S$, Korst $L$ et al. Cesarean versus vaginal delivery: Whose risks? Whose benefits? Am J Perinatol 2012; 29(1): 7-18.

9. Subhashini R, Uma N. Changing trends in Caesarean delivery. IAIM 2015; 2(3): 96-102.

10. Jawa A, Garg S, Tater A et al. Indications and rates of lower segment caesarean section at tertiary care hospital-an analytical study. Int J Reprod Contracept Obstet Gynecol 2016; 5(10): 3466-3469.

11. Preetkamal, Kaur $\mathrm{H}, \mathrm{Nagpal} M$. Is current rising trend of cesarean sections justified? Int J Reprod Contracept Obstet Gynecol 2017; 6(3): 872-876.

12. Das RK, Trimal Subudhi K, Mohanty RK. The rate and indication of caesarean section in a tertiary care 
teaching hospital eastern India. International Journal of Contemporary Pediatrics 2018; 5(5): 1733-1739.

13. Singh G, Gupta ED. Rising incidence of caesarean section in rural area in Haryana, India: a retrospective analysis. Internet J Gynecol Obstet 2013; 17(2): 1-5.

14. Stanton C, Ronsmans C. Recommendations for routine reporting on indications for caesarean delivery in developing countries. Birth 2008; 35(3): 204-211.

15. Torloni MR, Betran AP, Souza JP et al. Classification for caesarean section: a systematic review. PLoS One 2011; 6: e1456.

16. Desai $E$, Leuva $H$, Leuva B et al. A study of primary caesarean section in multipara. Int J Reprod Contracept Obstet Gynecol 2013; 2(3): 320-324.

17. Jain $M$, Patel A. A cross sectional study of rate, indications and complications of primary caesarean section. Int J Reprod Contracept Obstet Gynecol 2016; 5(6): 1814-1819.

18. Sarma P, Boro RC, Acharjee PS. An analysis of indications of caesarean sections at Tezpur medical college and hospital, Tezpur (a government hospital). Int J Reprod Contracept Obstet Gynecol 2016; 5: 1364-1367.

19. Chavda D, Goswami K, Dudhrejiva K. A cross sectional study of 1000 lower segment cesarean section in obstetrics and gynecology department of P. D. U Medical College, Rajkot, Gujarat, India. Int J Reprod Contracept Obstet Gynecol 2017; 6(4): 1186-1191.

20. Nikhil A, Desai A, Vijay K, et al. Analysis of trends in LSCS rate and indications of LSCS: a study in a Medical College Hospital GMERS, Sola, Ahmedabad. Int J Pharm Bio-Sci 2015; 2(1): 1-5.

21. Bade $P$, Kendre $V$, Jadhav $Y$ et al. An analysis of indications for caesarean section at government medical college, Latur. Intern J Recent Trends Sci Technol 2014; 11(1): 6-8.

22. Magann EF, Evans S, Hutchinson M et al. Postprtum hemorrhage after cesarean delivery: an analysis of risk factors. South Med J 2005; 98(7): 681-685.

23. Kumar N. Postpartum Hemorrhage; a Major Killer of Woman: Review of Current Scenario. Obstet Gynecol Int J 2016; 4(4): 00116.

24. Santhanalakshmi C, Gnanasekaran V, Chakravarthy AR. A retrospective analysis of cesarean section in a tertiary care hospital. Int J Sci Res 2015; 4: 2097-2099.

25. Hansen AK, Wisborg K, Uldbjerg $\mathrm{N}$ et al. Elective caesarean section and respiratory morbidity in the term and near-term neonate. Acta Obstetricia et Gynecologica 2007; 86: 389-394. 